\title{
Self-Discrepancies and Vulnerability to Body Dissatisfaction and Disordered Eating
}

\author{
Timothy J. Strauman \\ University of Wisconsin-Madison
}

\author{
Jennifer Vookles, Veronica Berenstein, \\ and Shelly Chaiken \\ New York University
}

\author{
E. Tory Higgins \\ Columbia University
}

\begin{abstract}
Two studies explored the relevance of self-discrepancies for body dissatisfaction and disordered eating. In Study 1, actual:ideal self-discrepancies of female undergraduates correlated with body shape dissatisfaction independent of Ss' body mass and number of appearance-related self-beliefs; actual:ought discrepancy was discriminantly associated with anorexic-related attitudes and behaviors. In Study 2 (using a mixed-gender sample), bulimic-related behaviors were associated with a form of actual:ideal discrepancy (unfulfilled positive potential) whereas anorexic-related symptoms were associated with actual.ought discrepancy. Both genders showed the predicted relations between self-discrepancies and disordered eating, and the predicted associations remained even when appearance-related attributes were excluded from scoring of self-discrepancies.
\end{abstract}

Eating disorders represent complex, prevalent, and significant health problems, particularly among adolescents and young adult women. Despite increasing research addressing the etiology of these problems, it remains unclear what psychological characteristics represent precursors of pathological eating behavior (American Psychiatric Association, 1987). Nonetheless, a sizable literature implicates sociocultural (e.g. Boskind-Lodahl, 1976; Rodin, Silberstein, \& Striegel-Moore, 1985), social cognitive (e.g., Chaiken \& Pliner, 1987; Mori, Chaiken, \& Pliner, 1987; Polivy, Herman, Jazwinski, \& Olmsted, 1984), and psychodynamic (e.g., Bruch, 1973, 1982) factors as precursors of eating-related problems.

Researchers and clinicians have implicated the self-concept in vulnerability to appearance-related and eating-related difficulties (Cash \& Green, 1986; Markus, Hamill, \& Sentis, 1987). Self-concept deficiencies may contribute significantly to the development of the negative self-evaluation, misperceptions of internal emotional and somatic states, and disturbed eating patterns characteristic of these syndromes (Mori et al., 1987). Strober and Goldenberg (1981) and Sugarman, Quinlan, and Devenis (1982) reported that self-concept disturbances tend to underlie body image distortion in eating-disordered subjects. Strauss and Ryan (1987) concluded that eating-disordered individuals exhibit poorer self-concept than matched controls.

This research was supported by a Biomedical Research Support Grant from the Graduate School of the University of WisconsinMadison to Timothy J. Strauman, by a National Science Foundation fellowship to Jennifer Vookles, and by National Institute of Mental Health Grant MH 39429 to E. Tory Higgins.

Correspondence concerning this article should be addressed to Timothy J. Strauman, Department of Psychology, University of Wisconsin, 1202 West Johnson Street, Madison, Wisconsin 53706, or to E. Tory Higgins, Department of Psychology, Columbia University, Schermerhorn Hall, New York, New York 10027.
Both family systems (Strober, 1982) and psychodynamic (Bruch, 1982) theorists have also suggested that unresolved issues surrounding individuation and self-definition may predispose individuals to eating disorders.

\section{Self-Discrepancy Theory}

We conducted this research to determine whether self-discrepancy theory (Higgins, 1987, in press) could identify which kinds of self-concept problems are associated with body dissatisfaction and disordered eating. The theory distinguishes among different types of discomfort that individuals holding incompatible self-beliefs may experience and relates different kinds of emotional vulnerabilities to different types of discrepancies that individuals may possess. The theory postulates domains of self including the actual self (a representation of the attributes that the individual or a significant other believes he or she actually possesses), the ideal self (a representation of the attributes that the individual or a significant other would ideally like him or her to possess), and the ought self (a representation of the attributes that the individual or a significant other believes it is his or her obligation or duty to possess). The ideal and ought self represent self-evaluative standards, or self-guides. Discrepancies between the actual self and self-guides lead to negative emotional-motivational states. The negative states associated with self-discrepancy, in turn, can lead to patterns of emotional distress as well as self-defeating behavior (Strauman, 1989a). As maladaptive eating behaviors involve both self-evaluative and self-regulatory processes, we sought to determine whether particular types of discrepant self-beliefs would be related to specific eating-related problems. Demonstrating that general selfdiscrepancies (as structural characteristics of the se'f that are independent of the content of individuals' self-belie's) were associated with disordered eating would represent a new avenue 
for exploring the psychological antecedents of body dissatisfaction and eating disorders.

Higgins (1989a) presented a developmental scheme for the emergence of self-guides that is relevant here. Advances in intellectual development are accompanied by the acquisition of self-other contingency knowledge, which in combination with the individual's social reinforcement experiences helps to establish motivationally significant internalized standards for behavior (self-guides). There are trade-offs associated with the development of stronger versus weaker self-guides that have implications for vulnerability to emotional distress (Higgins, 1989b). Although having weak self-guides tends to be associated with such problems as disobedience, aggressiveness, lack of responsibility, and antisocial behavior, the acquisition of strong self-guides (despite certain self-regulatory benefits) also can be associated with emotional vulnerabilities. Specifically, strong self-guides lead to increases in both the emotional intensity of self-evaluation and the motivation to reduce self-discrepancies. Discrepancy-based motivational states induce negative affect and trigger self-regulatory processes aimed at reducing the discrepancy between the actual self-state and relevant selfguides. When individuals are unable to reduce the discrepancy, they will experience more powerful and persistent negative affect. A psychological situation is created in which individuals are increasingly likely to experience intense emotional distress over longer periods of time. We postulate that such chronic negative self-evaluation (along with failure to adequately self-regulate) might contribute to the emergence of body dissatisfaction and disordered eating.

\section{Self-Beliefs, Gender, and Disordered Eating}

Variation in the strengths of self-guides that boys and girls acquire represents one possible contribution to gender differences in the incidence of emotional and behavior disorders (Rutter \& Garmezy, 1983; Simmons \& Blythe, 1987). Such disparity may arise from differences between boys and girls in interactions with caretakers that provide self-other contingency information (e.g., Parke \& Slaby, 1983; Rothbart \& Rothbart, 1976). More pressure is placed on girls to be nurturant, obedient, and socially responsible. Girls are far more closely supervised; they are more restricted and controlled, and their mistakes are responded to more quickly. Thus, the literature has suggested that girls are likely to acquire stronger self-guides than boys. This reasoning is also congruent with gender differences in the incidence of conduct disorders. Because girls tend to have stronger self-regulatory processes, they would be expected to show more behavioral control than boys. Parke and Slaby (1983) and Rutter and Garmezy have reported a higher proportion of boys than girls having conduct disorders or antisocial behavior problems throughout childhood. In contrast, body dissatisfaction and maladaptive eating frequently involve overcontrol, whereby individuals struggle to regulate their weight and appearance (e.g., Bruch, 1982). ${ }^{1}$

The trade-offs associated with acquisition of strong selfguides help account for the increased emotional vulnerabilities of girls. Between the juvenile period and adolescence, there is a shift in the type of self-attributes that are valued and sought
(Higgins \& Eccles-Parsons, 1983). Self-attributes valued during preschool and juvenile periods (e.g., neat, polite, and nonaggressive) can usually be attained through high levels of motivation to do so. Later standards based on popularity and attractiveness (Simmons \& Blythe, 1987), relative intelligence (Ruble, 1983), or other attributes that rely on social comparison are difficult to match through high motivation alone. The fact that adolescents are relatively less able to fulfill self-guides leaves them more vulnerable to the negative affect associated with self-discrepancies. Therefore, because adolescent girls are likely to have stronger self-guides than boys, we expect that girls would tend to be more emotionally vulnerable. The differential strength of self-guides in girls versus boys, along with the increased importance of standards that are more difficult to match during the juvenile and adolescent periods (e.g., appearance), is consistent with the modal onset of body dissatisfaction and disordered eating in girls during adolescence.

The present research examines the relations between selfdiscrepancies and vulnerability to body dissatisfaction and disordered eating. Study 1 involves a sample of female undergraduates, the population most likely to manifest such difficulties. However, our view is that vulnerability to body dissatisfaction and disordered eating is not limited to specific self-guide content or to girls and women. Although better appearance and desirable body characteristics are likely adolescent goals, the content of self-guides is not necessarily the pathogenic element. Instead, we emphasize the individual's ability to achieve matches between the actual self and self-guides. Although it is likely that women will acquire stronger self-guides than men, men whose self-other contingency history led to the acquisition of strong self-guides could also be vulnerable to body concerns and maladaptive eating behaviors (Andersen, 1986). In Study 2 , we predict the same associations between different self-discrepancies and anorexic versus bulimic symptoms respectively for both women and men. With respect to the question of self-guide content, we predict that the association between self-discrepancies and maladaptive eating will remain even when appearance-related attributes are excluded from measures of discrepancy.

\section{Study 1: Self-Discrepancy, Body Dissatisfaction, and Maladaptive Eating in Female Undergraduates}

Self-discrepancy theory postulates that actual:ideal discrepancy is associated with vulnerability to dejection (e.g., dissatisfaction, disappointment, or shame), whereas actual:ought discrepancy is associated with vulnerability to agitation (e.g., fear, worry, or guilt). Actual:ideal discrepancy has been shown to predict dissatisfaction with self (e.g., Higgins, Klein, \& Strauman, 1985); thus, we expected that body dissatisfaction would be discriminantly associated with this discrepancy, and particularly a discrepancy in which the ideal self-standard represents one's own standpoint-an actual:own versus ideal:own (AI) dis-

\footnotetext{
' Whereas bulimics typically report feeling a loss of control over their eating, the binge-purge cycle represents a clear instance of pathological overregulation.
} 
crepancy. Several investigators have reported that body shape dissatisfaction involves the belief that one's appearance or physical attributes do not meet some personally relevant ideal standard (Cash \& Green, 1986; Lerner \& Karabenick, 1974; Lerner, Karabenick, \& Stuart, 1973). We predicted a different self-discrepancy correlate for anorexic-related behaviors and attitudes. According to the Diagnostic and Statistical Manual of Mental Disorders, third edition, revised (DSM-III-R; American Psychiatric Association, 1987), characteristic features of anorexia include acute morbid and persistent fears (especially of appearing fat), an intense drive for thinness, disturbance in the way in which one's weight and shape are experienced, and self-punitive behaviors. Anorexic patients tend to be obedient, well-behaved, and conscientious (Bruch, 1973, 1982); they are characteristically described as anxious, guilty, and working to live up to the demands of others. These reports of self-punitiveness, intense fear, and working to meet others' demands are consistent with an actual/own:ought/other (AOO) discrepancy. Moreover, Higgins et al. (1985) found that weight loss (a diagnostic criterion for anorexia) was more strongly correlated with actual:ought than with actualideal discrepancy. Thus, the model suggests that anorexiclike behaviors would be discriminantly associated with $\mathrm{AOO}$ discrepancies.

We hypothesized that specific self-discrepancies would be associated with vulnerability to body dissatisfaction and anorexic-related problems; AI discrepancies would be more strongly associated with body dissatisfaction, and AOO discrepancies would be more strongly associated with anorexic-related problems. We also hypothesized that these discriminant associations would be manifested even after controlling statistically for other known predictors of body dissatisfaction and maladaptive eating. Two such predictors were used: the subject's body mass and the presence of appearance-related personal constructs (i.e., the content of subjects' self-beliefs). Both variables have been shown to be reliably associated with vulnerability to eating-related problems (e.g., Fransella \& Crisp, 1979; Strober, 1986).

\section{Method}

\section{Subjects}

Subjects were 138 female undergraduates in a Psychology of Personality course who participated in the study described as a comparison of personality questionnaires for course credit. Of this group, $128 \mathrm{com}-$ pleted all four measures, and their data were included in the analysis. The mean age of the sample was 21.0 years $(S D=3.2$, range $=18-40)$; the mean reported weight was 128.9 pounds $(S D=18.1$, range $=93-$ 200). The mean weight was within the normal range according to standard height and weight actuarial tables (Metropolitan Life Insurance Company, 1983). Body mass index (BMI) in kilograms per square meter was calculated by using reported height and weight. The mean BMI for the present sample was $21.09(S D=2.42$, range $=16.68-$ 29.59). Nine subjects (7\%) had a BMI greater than 25.0 (in the "overweight" range; Bray, 1986), and 21 subjects (16\%) had a BMI less than 19.0 (in the "underweight" range; Garrow, 1986).

\section{Measures and Procedure}

Subjects received a packet containing four questionnaires with a precoded identification number. They were requested to complete the forms in the order presented at home that evening. The following questionnaires (in order of presentation) were included:

1. Consent form/demographics sheet. A one-page form was used to obtain informed consent and to record the subject's age, height, and weight. The height and weight questions were included with a list of several items described as a "standard health inquiry" so as not to call undue attention to them.

2. Selves Questionnaire (Higgins, Bond, Klein, \& Strauman, 1986). This measure asks subjects to list traits or attributes for a number of self-states (e.g. actual/own, ideal/own, or ought/other) that constitute different domain/standpoint combinations within the self. Two sections were administered, the first involving the respondent's "own" standpoint and the second involving the standpoints of the respondent's "mother," "father," and "closest friend." Each page of the questionnaire concerned a particular self-state, for example, "Please list the attributes of the type of person you think you actually are" (the actual/own self-state). By having subjects spontaneously list the attributes associated with their self-states (instead of a checklist-type procedure), the likelihood that the attributes obtained would be chronically accessible and personally significant was increased (Higgins, King, \& Mavin, 1982). Subjects also rated the extent or extremity of each attribute, using a scale ranging from slightly (1) to extremely (4).

A two-stage process was used to calculate the magnitude of discrepancy between the actual/own self-state and each self-guide. First, each attribute of the actual/own self-state was compared with the attributes of the self-guide, with four types of at tribute-pair relationship possible: (a) match, in which the actual/own attribute and the self-guide attribute were synonymous and differed in their extent ratings by no more than 1 (e.g., actual/own: "moderately honest" vs. ought/other: "very honest"); (b) mismatch of extent, in which the attributes were synonymous but differed in their extent ratings by greater than 1 (e.g., actual/own: "slightly intelligent" vs. ideal/own: "extremely intelligent"); (c) mis match, in which the attributes were antonyms (e.g. actual/own: "shy" vs. ought/other: "outgoing"); and (d) nonmatch, in which the attribute pairs were neither synonyms nor antonyms. Nonmatches were not included in calculating self-discrepancy scores. The second step was to quantify the magnitude of discrepancy. Weights were assigned to categories as follows: matches and mismatches of extent were given weights of -1 and 1 respectively, and true mismatches were given a weight of 2 (Higgins, 1987). Each discrepancy score was obtained by summing the weights for all matches and mismatches pertaining to that pair of selfstates. In calculating AOO discrepancy scores, the ought/other selfguide (i.e., among "mother," "father," and "closest friend") that yielded the highest AOO discrepancy score was used. Subjects listed an average of 6.5 attributes for each self-state (each page permitted a maximum of 10 attributes); $62 \%$ of these attributes were classified as nonmatches. The overall interrater reliability (intraclass correlation) of the self-discrepancy measure was .87 .

In addition to scores for $\mathrm{AI}$ and $\mathrm{AOO}$ discrepancies, each subject was assigned a score denoting the number of chronically accessible constructs concerning appearance or body shape (ACA) among the self-guide attributes listed in the Selves Questionnaire. This measure was included to assess the alternative hypothesis that the presence of an appearance-related self-guide per se would be associated with greater body dissatisfaction and vulnerability to maladaptive eatingrelated behaviors.

3. Body Shape Questionnaire (BSQ; Cooper, Taylor, Cooper, \& Fairburn, 1987). This 34-item checklist assesses concerns about body shape and appearance in both normal and clinical populations. Each item consists of a question concerning how often the subject felt a particular way about her appearance during the past 4 weeks. Subjects respond to each item on a 6-point scale ranging from never (1) to always 
(6). Each subject was assigned a total score on the BSQ by summing individual item scores.

4. Eating Attitudes Test (EAT; Garner \& Garfinkel, 1979). The EAT is a 40 -item checklist measure of eating-related attitudes and behaviors. Subjects rated the extent to which the statement was true for them on a 6-point scale ranging from always to never. The original scoring method was used: For each item the most symptomatic response (usually always) received a score of 3 , the next most symptomatic response (usually very often) received a score of 2 , the third most symptomatic response (usually often) received a score of 1 , and all other responses received a score of 0 . Subjects were assigned a total EAT score by summing across the 40 items, and three subscale scores representing aspects of maladaptive eating relevant to the present hypotheses (Dieting, Bulimia/Food Preoccupation, and Oral Control) were also calculated. Garner, Olmstead, Bohr, and Garfinkel (1982) presented evidence suggesting that the EAT was a reliable and valid measure of maladaptive eating behavior in both nonclinical and clinical samples.

\section{Results and Discussion}

\section{Characteristics of the Sample}

Of the total sample, $38(30 \%)$ included at least one construct related to appearance among the self-guide attributes listed on the Selves Questionnaire; 11 (8.6\%) listed two appearance-related constructs. Of the 49 appearance-related constructs listed, the most frequent were "attractive" (16), "beautiful" (11), and "thin" or "thinner" (9). The mean BSQ total score was 99.5 $(S D=35.4)$, marginally higher than the community sample mean score of 81.5 reported by Cooper et al. (1987). A total of 25 subjects (20\%) had BSQ scores greater than 136 , the mean score for a sample of bulimic patients reported by Cooper et al. The mean EAT 40-item total score in the present sample was $20.9(S D=14.1)$, slightly greater than the mean score for a normal control sample $(M=15.6)$ reported by Garner and Garfinkel (1979). A total of 29 subjects (21\%) had EAT-40 scores greater than 30 , the maximally discriminant cutoff score for identifying anorexic women reported by Garner and Garfinkel. Fifteen subjects had both elevated BSQ $(>136)$ and elevated EAT $-40(>30)$ total scores.

\section{Zero-Order ( $r$ ) and Partial Correlation (pr) Analyses}

Table 1 presents the correlations among the study variables. Several features of the zero-order matrix may be noted. First, the BSQ and EAT scores were highly correlated, $r(126)=.68$,

Table 1

Zero-Order Correlations Among the Measures in Study 1

\begin{tabular}{lcccccc}
\hline Measure & 1 & 2 & 3 & 4 & 5 & 6 \\
\hline 1. BMI & - & & & & & \\
2. AI & -.02 & - & & & & \\
3. AOO & -.01 & $.50^{* * *}$ & - & & & \\
4. ACA & $.18^{*}$ & .14 & .12 & - & & \\
5. BSQ & $.43^{* * *}$ & $.29^{* *}$ & $.21^{*}$ & $.39^{* * *}$ & - & \\
6. EAT & .15 & $.18^{*}$ & $.30^{* * *}$ & $.35^{* * *}$ & $.68^{* * *}$ & - \\
\hline
\end{tabular}

Note. $\quad N=128 . \mathrm{BMI}=$ Body Mass Index; $\mathrm{AI}=$ actual/own;ideal/own discrepancy; $A O O=$ actual/own:ought/other discrepancy; $A C A=a c-$ cessible constructs for appearance; $B S Q=$ Body Shape Questionnaire total score; EAT = Eating Attitudes Test total score.

${ }^{*} p<.05$. ${ }^{* *} p<.01$. $^{* * *} p<.001$. $p<.0001$, which decreased the likelihood of finding discriminant relations between each measure and each self-discrepancy. Second, all four predictor variables (BMI, AI, AOO, and ACA) were at least marginally correlated with both BSQ and EAT, ranging from $.15(p<.08)$ to $.43(p<.001)$. Both $\mathrm{AI}$ and $\mathrm{AOO}$ were significantly correlated with both BSQ and EAT. Third, with the exception of the expected moderate correlation between $\mathrm{AI}$ and $\mathrm{AOO}, r(126)=.50, p<.001$ (Higgins, 1987), the predictor variables showed only a limited degree of intercorrelation.

Not all self-discrepancies were associated with body dissatisfaction and maladaptive eating. Actual/own versus ideal/other discrepancy did not significantly predict either BSQ or EAT scores, $r \mathrm{~s}(126)=.06$ and .11 , respectively. Similarly, actual/own: ought/own discrepancy did not significantly predict either BSQ or EAT scores, $r s(126)=.14$ and .15 , respectively, both $p s>.09$. These data provide initial support for the hypothesis that only particular self-discrepancies are associated with body dissatisfaction and anorexic-related eating behaviors, respectively.

To test for discriminant associations between AI versus $\mathrm{AOO}$ self-discrepancy and vulnerability to body dissatisfaction versus anorexic-related behaviors, partial correlations were calculated in which the relation between each type of self-discrepancy and BSQ/EAT was examined while statistically controlling for both the other discrepancy and the other measure of maladaptive attitudes and behaviors. This double-partial strategy provides a stringent test of the discriminant hypothesis, particularly as the two discrepancy scores and the two distress measures were both intercorrelated. ${ }^{2}$ The predictions regarding discriminant validity were supported. AI remained a significant predictor of BSQ even with the influence of $A O O$ and EAT controlled, $\operatorname{pr}(124)=.19, p<.05 ;$ AOO did not predict BSQ after AI and EAT were controlled, $p r(124)=.07, n s$. AOO remained significantly associated with EAT even after partialing out AI and BSQ, $p r(124)=.27, p<.01$; AI did not predict EAT after controlling for AOO and $\mathrm{BSQ}, \operatorname{pr}(124)=-.02$, $n s$.

Additional support for our predictions was obtained from partial correlation analyses of the three EAT subscales. Garner et al. (1982) presented evidence that the Dieting and Oral Control subscales were associated with anorexic symptomatology, whereas the Bulimia/Food Preoccupation subscale was more strongly associated with bulimic behaviors (in both anorexic and bulimic individuals). We hypothesized that AI would remain significantly correlated with the Bulimia/Food Preoccupation subscale after partialing out $\mathrm{AOO}$ and the Dieting and Oral Control subscales; likewise, we expected that AOO would

\footnotetext{
${ }^{2}$ The degree of association between BSQ and EAT total scores appears to represent an accurate appraisal of the co-occurrence of body dissatisfaction and dysfunctional eating behavior in nonclinical samples. As Garner, Olmsted, Bohr, and Garfinkel (1982) and others have noted, even in clinical populations it is relatively atypical to find "pure" instances of anorexia or bulimia. We suggest that the typical mixed symptom picture in both subclinical and clinical eating disorders can be conceptualized by means of self-discrepancy theory, in which coexisting sources of vulnerability to emotional distress (e.g., actual:ideal and actual:ought discrepancies) are postulated to lead to distinct emotional outcomes.
} 
remain significantly correlated with the Dieting and Oral Control subscales after partialing out AI and the Bulimia/Food Preoccupation subscale. Both predictions were supported: For the AI-Bulimia/Food Preoccupation subscale correlation, $p r(124)=.18, p<.05$; for the AOO-Dieting and AOO-Oral Control correlations, $p r s(124)=.19$ and .18 , respectively, both $p \mathrm{~s}<.05$.

\section{Hierarchical Multiple Regression Analyses}

The second hypothesis concerned the predictive power of self-discrepancies beyond other relevant variables. We expected that self-discrepancy would account for variance in BSQ and EAT beyond that predicted by BMI and the presence of ACA. To test this hypothesis, hierarchical multiple regressions predicting BSQ and EAT, respectively, were performed. Statistical tests for increments in variance accounted for with the addition of predictor variables used the Type II error model recommended by Cohen and Cohen (1975). As order of entry in hierarchical analyses is critical, competing predictor variables (BMI and ACA) were entered before self-discrepancy variables, so that shared variance would not contribute to any increment in $R^{2}$ obtained when $\mathrm{AI}$ or $\mathrm{AOO}$ were added. Interaction terms were also included to determine whether the combination of self-discrepancy and the presence of an ACA would account for additional variance. Table 2 lists the order in which each predictor variable was entered, the cumulative $R^{2}$ at each step, the increment in $R^{2}$ over the previous step, the $F$ value for the increment in $R^{2}$, and the significance level for the $F$ test. Because different orders of variable entry were used for BSQ and EAT, each analysis is discussed separately.

Table 2

Hierarchical Multiple Regression Analyses Predicting Body Shape Questionnaire and Eating Attitudes Test Scores in Study 1

\begin{tabular}{|c|c|c|c|c|}
\hline $\begin{array}{l}\text { Variable } \\
\text { entered }\end{array}$ & $\underset{R^{2}}{\text { Cumulative }}$ & $\begin{array}{l}\text { Increment } \\
\quad \text { in } R^{2}\end{array}$ & $\begin{array}{l}F(1,121) \text { for } \\
\text { increment }\end{array}$ & $\begin{array}{c}p \text { for } \\
\text { increment }\end{array}$ \\
\hline \multicolumn{5}{|c|}{ Body Shape Questionnaire total score } \\
\hline BMI & .195 & .195 & 37.81 & $<.001$ \\
\hline $\mathrm{ACA}$ & .290 & .095 & 18.42 & $<.001$ \\
\hline $\mathrm{AOO}$ & .327 & .037 & 7.17 & $<.01$ \\
\hline AI & .352 & .025 & 4.85 & $<05$ \\
\hline $\mathrm{AI} \times \mathrm{ACA}$ & .375 & .023 & 4.46 & $<.05$ \\
\hline $\mathrm{AOO} \times \mathrm{ACA}$ & .376 & .001 & 0.19 & $n s$ \\
\hline \multicolumn{5}{|c|}{ Eating Attitudes Test total score } \\
\hline BMI & .028 & .028 & 4.43 & $<.05$ \\
\hline ACA & .120 & .092 & 14.57 & $<.001$ \\
\hline AI & .144 & .024 & 3.80 & $<.07$ \\
\hline $\mathrm{AOO}$ & .203 & .059 & 9.34 & $<.01$ \\
\hline $\mathrm{AOO} \times \mathrm{ACA}$ & .227 & .024 & 3.80 & $<.07$ \\
\hline$A I \times A C A$ & .229 & .002 & 0.32 & $n s$ \\
\hline
\end{tabular}

Note. $\quad N=128 . \mathrm{BMI}=$ Body Mass Index; $\mathrm{AI}=$ actual/own:ideal/own discrepancy. $\mathrm{AOO}=$ actual/own:ought/other discrepancy; $\mathrm{ACA}=\mathrm{ac}-$ cessible constructs for appearance; $\mathrm{AOO} \times \mathrm{ACA}=\mathrm{AOO} / \mathrm{ACA}$ interaction; $\mathrm{Al} \times \mathrm{ACA}=\mathrm{Al} / \mathrm{ACA}$ interaction.
For BSQ, all four predictor variables produced statistically significant increments in $R^{2}$. BMI, which showed the largest zero-order correlation with BSQ, was entered first and accounted for the greatest proportion of variance $(19.5 \%)$. The addition of ACA also resulted in a sizable increase in $R^{2}(9.5 \%)$, validating the notion that dissatisfaction with one's body or appearance is associated with the presence of ACAs. The two self-discrepancy variables were then entered sequentially, with $\mathrm{AOO}$ before $\mathrm{AI}$ (based on the prediction that $\mathrm{AI}$ would be discriminantly associated with BSQ). The addition of AOO provided a significant increment in $R^{2}(3.7 \%)$, not surprising given the high correlation between $\mathrm{AOO}$ and $\mathrm{AI}$; however, when AI was added as the fourth predictor variable, it also produced a significant increment in $R^{2}$ (an additional 2.5\%) despite its sizable correlation with $\mathrm{AOO}{ }^{3}$ The AI $\times$ ACA interaction (the interaction term more likely to be predictive of BSQ scores) was entered as the fifth step in the analysis and obtained a modest but significant increment in $R^{2}(2.3 \%)$. The $\mathrm{AOO} \times$ ACA interaction was entered in the final step and did not account for additional variance in BSQ scores. Examination of the regression coefficient for the AI $\times$ ACA interaction term indicated a positive association between interaction scores and BSQ; that is, subjects with both substantial AI discrepancy and an ACA self-guide were more highly vulnerable to body dissatisfaction.

For EAT, BMI was also entered first and accounted for a modest but statistically significant portion of variance (2.8\%). $A C A$, the second variable entered, again proved to be a significant predictor (9.2\%) of the variance in EAT scores. Both selfdiscrepancy scores accounted for additional variance in EAT. AI was entered on the third step, resulting in a marginally significant increment in $R^{2}(2.4 \%, p<.07)$. AOO, expected to be more strongly associated with EAT scores, was then entered and produced an increment in $R^{2}$ of $5.9 \%{ }^{4}$ The $\mathrm{AOO} \times \mathrm{ACA}$ interaction term (considered more likely to be predictive of EAT scores) was entered as the fifth step of the analysis. This step accounted for a marginally significant additional portion of BSQ score variance $(2.4 \%, p<.07)$. The final step, adding the AI $\times$ ACA interaction, did not result in a meaningful increment in $R^{2}$. The regression coefficient for the AOO $\times \mathrm{ACA}$ interaction term was positive, indicating that subjects with both $A O O$ discrepancy and an ACA self-guide were more highly vulnerable to anorexic-related behaviors.

\section{Summary}

Our predictions regarding psychological correlates of vulnerability to body dissatisfaction and anorexiclike attitudes and behaviors, derived from self-discrepancy theory and related literatures, were supported. AI discrepancy was discriminantly

\footnotetext{
${ }^{3}$ As an additional test of our specificity hypothesis, we also performed this analysis adding AI before AOO. As would be expected, the addition of $\mathrm{AI}$ resulted in a significant increment in $R^{2}$, and the addition of AOO did not.

${ }^{4}$ We also performed this analysis adding AOO before AI. As expected, the addition of $\mathrm{AOO}$ to the model resulted in a significant increment in $R^{2}$, and the addition of AI did not.
} 
related to body dissatisfaction, and AOO discrepancy was discriminantly predictive of anorexic-related eating problems. These findings suggest a possible contributory role for the motivational and affective consequences of self-discrepancies in vulnerability to body dissatisfaction as well as disordered eating.

\section{Study 2: Self-Discrepancy, Bulimic Versus Anorexic Behaviors, and Gender}

The second study was conducted to replicate and extend the findings of Study 1 in two ways. The initial study (a) did not attempt to differentiate between anorexic- and bulimic-related behaviors in nonclinical samples and (b) was limited to a female population. The second study differentiates between these behaviors and examines whether the associations observed in the initial study would be obtained in a mixed-sex sample.

We expected that $\mathrm{Al}$ would be discriminantly associated with bulimic-type eating problems for several reasons. The DSM$I I I-R$ criteria for the diagnosis of bulimia include "persistent overconcern with body shape and weight" as a cardinal feature of the syndrome; as AI was shown to correlate with body dissatisfaction, individuals manifesting bulimic behaviors may be likely to possess AI discrepancies. In addition, the BSQ has been reported to be more closely associated with measures of bulimia than with measures of anorexia (Cooper et al., 1987). Furthermore, $D S M-I I I-R$ indicates that depressed mood is more commonly observed among bulimics than among anorexics (e.g., Lee, Rush, \& Mitchell, 1985). A number of authors have reported a relation between bulimic symptoms and chronic depressive affect (Hudson, Laffer, \& Pope, 1982; Walsh et al., 1982). Lee et al. (1985) argued that bulimia might be a variant of depression, because symptoms of bulimia such as dissatisfaction, discouragement, and binge eating are also indicative of depression. On the basis of the association between AI and depressive symptomatology (Strauman, 1989b; Strauman \& Higgins, 1988), we predicted a significant relation between $\mathrm{AI}$ and bulimic behaviors in this nonclinical sample.

We were particularly interested in examining the relation between bulimic-type behavior and a variation of AI. Self-discrepancy theory has been expanded to include the can self, which is a representation of one's beliefs about one's capabilities or potential (Higgins, in press). The can self is not a self-guide like the ideal or ought self but is rather a domain of self-possibilities not unlike Bandura's notion of self-efficacy (Bandura, 1982). Higgins (in press) argued that the emotional significance of chronic failure to match one's ideal self-guides varies as a function of the relationship of the can self to the actual and ideal selves. When a person believes that he or she has the potential to fulfill ideals but nonetheless continually fails to meet this potential, the actual self is discrepant from both the ideal self and the can self. This pattern of self-beliefs represents the psychological situation of chronic failure to meet one's positive potential, or unfulfilled positive potential (UFPP). Although UFPP is postulated to be associated with dejection-related emotions, it represents a more specific emotional vulnerability and is also hypothesized to be associated with specific dejection-related emotions such as feeling like a failure, feeling a loss of control over one's life, feeling dissatisfaction with accomplishments, feeling helpless, having to push one's self to do anything, and not feeling energetic or alert. Garner and Garfinkel (1979), among others, have observed an association between feelings of helplessness, dissatisfaction, lethargy, and loss of control and bulimic attitudes and behaviors. A sense of lacking control over one's life (particularly with respect to behaviors and attributes relevant to one's self-guides) has been found to be associated with UFPP and is hypothesized to be a possible precursor of the bulimic syndrome.

We predicted that $\mathrm{AOO}$ would be specifically associated with anorexic-related behaviors and attitudes, whereas AI would be discriminantly associated with bulimiclike eating problems. In addition, we predicted that UFPP (as a form of AI discrepancy) would be even more strongly related to bulimic symptomatology than AI. We also hypothesized that these discriminant relations would be found for both men and women, in keeping with the model presented above. Finally, we expected that both hypotheses would be supported even when appearance-related self-guides were excluded from analyses.

\section{Method}

\section{Subjects}

Students in an introductory psychology class completed a test battery at the beginning of the semester. All subjects who completed a particular questionnaire (see below) were eligible for the latter portion of the study and were later offered the chance to participate in partial fulfillment of a course requirement. A total of 91 students (64 women and 27 men) completed both portions of the study. The mean age of this sample was 19.0 years $(S D=1.0$, range $=16-23)$.

\section{Measures and Procedure}

The Selves Questionnaire was the first measure administered in the initial battery. An expanded version of the Selves Questionnaire was used. In addition to the actual, ideal, and ought domains of self, the expanded version included the can self-domain (i.e., the subject's representation of the attributes that he or she believes he or she can possess; his or her expectations about capabilities or potential). The scoring procedure from Study 1 was used to calculate subjects' Al and AOO discrepancies. Each subject's UFPP score was determined by locating any matches on the can and ideal attribute lists. These matches were then compared to the actual list; the matches and mismatches were weighted and totaled in the usual fashion. For a second set of analyses, all discrepancy scores were recomputed by omitting any appearancerelated attributes from the calculations. As in Study 1, this analysis was performed to assess the predictive power of self-discrepancies independent of the presence or absence of appearance-related selfattributes.

Eight to 12 weeks later, subjects who volunteered to participate in the latter portion of the study participated in groups averaging 6 persons per session (range $=3-9$ ). Two questionnaire measures were administered, and all subjects completed the questionnaires in the same order. These questionnaires were the EAT (Garner \& Garfinkel, 1979) and the Binge Eating Scale (BINGE; Hawkins \& Clement, 1980). This latter measure contains 10 items designed to assess the presence and severity of binge eating as well as related attitudinal parameters. Because this scale was developed with an undergraduate population rather than a clinical bulimic sample, it was particularly appropriate for this study. 
The first item asks whether the subject ever binges; the remaining 9 items refer to characteristics of the binge-eating episodes. Responses are weighted with the least symptomatic response scored 0 and the most symptomatic response scored 3 . As suggested by Hawkins and Clement, the 9 items referring to symptom severity were averaged to yield a total score. Subjects who reported on the first item that they did not binge received a total score of 0 .

\section{Results and Discussion}

\section{Characteristics of the Sample}

Scores for the EAT and BINGE were comparable to other nonclinical samples. The mean EAT total score was $17.6(S D=$ 18.4), slightly greater than the mean for a normal control sample $(M=15.6)$ reported by Garner and Garfinkel (1979). Twelve subjects ( 11 women and I man) had EAT scores greater than 30 , the maximally discriminant cutoff score for identifying anorexic women reported by Garner and Garfinkel. The mean BINGE score was $0.41(S D=0.5)$. Despite the low sample mean, 57 subjects ( 44 women and $13 \mathrm{men}$ ) indicated at least some binge eating.

\section{Zero-Order and Partial Correlation Analyses}

The EAT and BINGE scores were highly intercorrelated $(r=$ $.73, p<.001$ ), as were the three types of self-discrepancy. Table 3 lists the zero-order correlations among the five study variables. Despite the degree of intercorrelation, $\mathrm{AOO}$ was more strongly associated with EAT scores than were the other two self-discrepancy variables $(r=.42, p<.001)$. Similarly, the EAT was more strongly associated with AOO than was the BINGE scale.

To test for discriminant associations between different selfdiscrepancies and bulimic-type versus anorexic-type behaviors, partial correlation analyses were performed, representing the association between a specific discrepancy and a specific type of maladaptive eating, controlling for the alternative type of discrepancy and eating problem. Table 4 contains partial correlations among the variables, whereas Table 5 reports the partial correlations with the discrepancy scores recomputed to exclude appearance-related constructs. Our predictions regard-

Table 3

Zero-Order Correlations Among Eating Disorder Scale Scores and Self-Discrepancy Variables in Study 2

\begin{tabular}{lccccc}
\hline Measure & 1 & 2 & 3 & 4 & 5 \\
\hline 1. AI & - & $.40^{* *}$ & $.53^{* * *}$ & $.22^{*}$ & .17 \\
2. AOO & & - & $.38^{* *}$ & $.42^{* *}$ & $.25^{*}$ \\
3. UFPP & & & - & .05 & .20 \\
4. EAT & & & - & $.73^{* * *}$ \\
5. BINGE & & & & - \\
\hline
\end{tabular}

Note. $\quad N=91 . \mathrm{AI}=$ actual/own:ideal/own discrepancy; $\mathrm{AOO}=\mathrm{ac}-$ tual/own:ought/other discrepancy; UFPP = unfulfilled positive potential; EAT = Eating Attitudes Test total score; BINGE = Binge Eating Scale score.

${ }^{*} p<.05 .^{* *} p<.01 .^{* * *} p<.001$. ing discriminant associations were supported. With the influence of $\mathrm{AI}$ and BINGE removed, AOO remained positively correlated with $\mathrm{EAT}, \operatorname{pr}(87)=.34, p<.001$; a significant association between $A O O$ and $E A T$ was also found when variance due to UFPP and BINGE was controlled, $p r(87)=.45, p<.001$. Conversely, whereas AI did not show significant discriminant association with BINGE, UFPP showed a strong positive correlation with the BINGE scale when the influence of $A O O$ and EAT was controlled, $p r(87)=.30, p<.01$. As Table 5 shows, this pattern of results was similar when discrepancy scores were recomputed excluding appearance-related attributes.

As in Study 1, we also examined the relations between the self-discrepancy measures and the subscales of the EAT. We hypothesized that $A O O$ would remain significantly correlated with the Dieting and Oral Control subscales after partialing out AI/UFPP and the Bulimia/Food Preoccupation subscale. This prediction was supported: Partial correlations between $A O O$ and the Dieting and Oral Control subscales (controlling for AI, UFPP, and the Bulimia/Food Preoccupation subscale) were significant, $p r(87)=.21$ and .33 respectively, both $p s<.05$. Conversely, this supplementary analysis did not indicate a discriminant relation between either AI or UFPP and the Bulimia subscale, $p r s(86)=.14$ and .15 , respectively.

\section{Analyses by Gender}

The present sample manifested the usual preponderance of women with maladaptive eating-related behaviors and attitudes (e.g., Hawkins \& Clement, 1980). Whereas 11 of the female subjects in our sample scored at 30 or above (the recommended cutoff score) on the EAT, only one of the male subjects had an EAT score above this cutoff. Scores on the eating questionnaires were correlated with gender (female subjects having higher scores): For the EAT, $r=.20, p<.03$; for the BINGE, $r=$ $.20, p<.03$.

To test whether discriminant relations between particular self-discrepancies and different kinds of eating-related prob-

Table 4

Partial Correlations Between Eating Disorder Scale Scores and Self-Discrepancy Scores in Study 2

\begin{tabular}{lcccr}
\hline Measure & AOO & AI & AOO & UFPP \\
\hline EAT & $.34^{* * *}$ & .01 & $.45^{* * *}$ & $-.31^{* *}$ \\
BINGE & -.11 & .05 & $-.22^{*}$ & $.30^{* *}$ \\
\hline
\end{tabular}

Note. $\quad N=91$. EAT $=$ Eating Attitudes Test total score; BINGE $=$ Binge Eating Scale score; $\mathrm{AI}=$ actual/own:ideal/own discrepancy; $\mathrm{AOO}=$ actual/own:ought/other discrepancy; UFPP = unfulfilled positive potential. For each correlation, the score on the alternate eating disorder scale and one discrepancy score are statistically controlled. In the second column, AI is partialed from AOO; in the third column, $A O O$ is partialed from $A I$; in the fourth column, UFPP is partialed from AOO; and in the fifth column, AOO is partialed from UFPP.

${ }^{*} p<.05 .{ }^{* *} p<.01{ }^{* * *} p<.001$. 
Table 5

Partial Correlations Between Eating Disorder Scale Scores and Self-Discrepancy Scores, Omitting AppearanceRelated Attributes in Study 2

\begin{tabular}{lcccr}
\hline Measure & AOO & AI & AOO & UFPP \\
\hline EAT & $.35^{* *}$ & .01 & $.46^{* *}$ & -.32 \\
BINGE & -.14 & .05 & $-.25^{*}$ & .34 \\
\hline
\end{tabular}

Note. $\quad N=91$. EAT $=$ Eating Attitudes Test total score; BINGE $=$ Binge Eating Scale score; $\mathrm{AI}=$ actual/own:ideal/own discrepancy; $\mathrm{AOO}=$ actual/own:ought/other discrepancy; UFPP = unfulfilled positive potential. For each correlation, the score on the alternate eating disorder scale and one discrepancy score are statistically controlled. In the second column, $\mathrm{AI}$ is partialed from $\mathrm{AOO}$; in the third column, AOO is partialed from AI; in the fourth column, UFPP is partialed from $A O O$; and in the fifth column, $A O O$ is partialed from UFPP. ${ }^{*} p<.02$. ${ }^{* *} p<.002$.

lems would hold for both men and women, partial correlation analyses were repeated for each gender. ${ }^{5}$ Table 6 contains the partial correlations for female and male subjects, respectively, using the original coding for discrepancies (i.e., including all self-guides). AOO was positively correlated with EAT for both female and male subjects when the influence of AI/UFPP and BINGE was controlled, and UFPP was positively correlated with BINGE scores of both genders when AOO and EAT were partialed out (although the $p r$ values did not reach significance for the male subjects). When the discrepancy scores were recoded to exclude any appearance-related attributes (Table 7), the hypothesized pattern of partial correlations was again obtained. For both sexes, AOO was positively correlated with EAT when AI/UFPP and BINGE were controlled. Among female subjects, UFPP was significantly correlated with BINGE when AOO and EAT were removed, and among male subjects this correlation approached significance.

Table 6

Partial Correlations by Gender Between Eating Disorder Scale Scores and Self-Discrepancy Scores in Study 2

\begin{tabular}{lcccc}
\hline \multicolumn{1}{c}{ Gender } & AOO & AI & AOO & UFPP \\
\hline Female $(n=64)$ & & & & \\
EAT & $.30^{* * *}$ & .05 & $.43^{* * * * *}$ & $-.33^{* * * *}$ \\
BINGE & -.08 & .07 & $-.21^{* *}$ & $.36^{* * * *}$ \\
Male $(n=27)$ & & & & \\
$\quad$ EAT & $.29^{*}$ & -.07 & $.41^{* * *}$ & $-.40^{* * *}$ \\
BINGE & $-.27^{*}$ & .07 & $-.29^{*}$ & .11 \\
\hline
\end{tabular}

Note. $\quad$ EAT $=$ Eating Attitudes Test total score $; \mathrm{BINGE}=$ Binge Eating Scale score; $\mathrm{AI}=$ actual/own:ideal/own discrepancy; $\mathrm{AOO}=$ actual/ own:ought/other discrepancy; UFPP $=$ unfulfilled positive potential For each correlation, the score on the alternate eating disorder scale and one discrepancy score are statistically controlled. In the second column, $\mathrm{AI}$ is partialed from $\mathrm{AOO}$; in the third column, $\mathrm{AOO}$ is partialed from AI; in the fourth column. UFPP is partialed from $A O O$; and in the fifth column, AOO is partialed from UFPP.

${ }^{*} p<.10$. $^{* *} p<.06$. ${ }^{* * *} p<.05$. $^{* * * *} p<.005$. $^{* * * * *} p<.001$. All $p$ s are one-tailed.
Table 7

Partial Correlations by Gender Between Eating Disorder Scale Scores and Self-Discrepancy Scores, Omitting AppearanceRelated Attributes in Study 2

\begin{tabular}{lcccc}
\hline Gender & AOO & AI & AOO & UFPP \\
\hline Female $(n=64)$ & & & & \\
EAT & $.30^{* * * *}$ & .09 & $.42^{* * * * *}$ & $-.31^{* * * *}$ \\
BINGE & -.10 & .03 & $-.21^{* * *}$ & $.36^{* * * * *}$ \\
Male $(n=27)$ & & & & \\
EAT & $.35^{* * *}$ & -.17 & $.54^{* * * * *}$ & $-.56^{* * * * *}$ \\
BINGE & $-.33^{* *}$ & .17 & $-.39^{* * *}$ & $.27^{*}$ \\
\hline
\end{tabular}

Note. $\mathrm{EAT}=$ Eating Attitudes Test total score; $\mathrm{BINGE}=$ Binge Eating Scale score; $\mathrm{Al}=$ actual/own:ideal/own discrepancy; $\mathrm{AOO}=$ actual/ own:ought/other discrepancy; UFPP = unfulfilled positive potential. For each correlation, the score on the alternate eating disorder scale and one discrepancy score are statistically controlled. In the second column, AI is partialed from $\mathrm{AOO}$; in the third column, $\mathrm{AOO}$ is partialed from $\mathrm{AI}$; in the fourth column, UFPP is partialed from $\mathrm{AOO}$; and in the fifth column, AOO is partialed from UFPP.

${ }^{*} p<.10 .^{* *} p<.06 .{ }^{* * *} p<.05 .^{* * * *} p<.01 .^{* * * * *} p<.001$. All $p$ s one-tailed.

\section{General Discussion}

We explored the relation between self-discrepancies and both body dissatisfaction and disordered eating in two undergraduate samples. The self-discrepancy model is comprehensive enough to consider a range of psychological phenomena associated with maladaptive eating: self-perception, self-evaluation, motivation, and self-regulation. The theory predicts which kinds of self-discrepancy will be associated with body dissatisfaction and with anorexic- and bulimic-related attitudes and behaviors and provides a framework for conceptualizing how disordered eating might emerge in both women and men.

As a developmental perspective on self-evaluation and affect, self-discrepancy theory offers a rationale for prediction of differential vulnerability to syndromes of emotional distress and maladaptive behavior (Higgins, in press). Our model for the acquisition of self-guides is highly applicable to the emergence of body image concerns and eating-related problems in adolescence. A number of researchers have suggested that the attitudinal and emotional aspects of body image arise from socialization patterns that are based on interpersonal and family relationships (e.g., Mori et al, 1987; Powers, Schulman, Gleghorn, \& Prange, 1987). The ability of the model to complement the predictive power of other psychological approaches to eating problems suggests the value of further investigation of self-beliefs and self-evaluation in this domain.

Our studies demonstrate that both the content and the structure of self-beliefs may represent vulnerability factors for body dissatisfaction and maladaptive eating behavior. The presence of one or more chronically accessible constructs related to appearance or body shape, particularly among one's motivation-

\footnotetext{
${ }^{5}$ In the analysis by gender, one-tailed significance levels were used because of the reduced sample size for each series of analyses (women, $N=64$; men, $N=27$ ).
} 
ally significant self-guides, predicted body dissatisfaction and tendencies to preoccupation with behaviors such as dieting. In fact, it would be difficult to conceive of body-shape-concerned or eating-disordered individuals not possessing some chronically accessible standard for appearance, body shape, and weight. Surprisingly, with a few exceptions (e.g., Fransella \& Button, 1983; Fransella \& Crisp, 1979), the role of construct accessibility in disordered eating has not been explored. In addition, what our research implies is that other aspects of self-beliefs, namely within-self structural discrepancies, may also be associated with the emergence of these problems. Our findings suggest that the psychological roots of dissatisfaction with one's appearance and maladaptive eating behavior are likely to include both specific standards for one's appearance and more generalized structural inconsistencies among self-beliefs.

Previous self-discrepancy research showed that self-discrepancies are cognitive structures, in that they manifest features characteristic of structures in long-term memory (Higgins, 1989c; Strauman \& Higgins, 1987). For example, they can be automatically activated by contextual features (Bargh, 1984) and can influence ongoing information processing without the individual's awareness. Exposure to contextual cues can activate self-discrepancies-and induce predictable motivational and affective states-despite the individual's desire to avoid such emotional consequences. Also, discrepancies are associated with syndromes of motivational change, physiological arousal, emotional experience, and behavior (Strauman, 1989b; Strauman \& Higgins, 1987). Activation of discrepant self-beliefs has significant consequences across a range of response channels rather than simply with in the conscious cognitive domain. The demonstrable influence of self-beliefs on both mood and behavior suggests that researchers would be premature to limit their investigations of body dissatisfaction and maladaptive eating to aspects of the self-concept explicitly involving appearance and body shape per se. We would expect that both men and women who possess chronic vulnerability to bodyand eating-related concerns would respond habitually (and unintentionally) to the wide range of cues in the social environment regarding appearance.

It is likely that no single perspective on the etiology of eatingrelated problems will be sufficient for understanding such complex and multidetermined behavioral syndromes. Even within the psychological domain, a number of factors-motivational, cognitive, interpersonal, and cultural-are likely to combine in the development of such problems. It becomes crucial to establish a range of usefulness for each approach to maximize its applicability. How might self-beliefs in general, and self-discrepancies in particular, fit within a comprehensive model of vulnerability to body dissatisfaction and eating problems?

While our data show that self-discrepancies are associated with disordered eating in both men and women, women in our culture tend to be more concerned about body weight and eating than men (Herman \& Polivy, 1980); eating disorders are also less prevalent among men (Garfinkel \& Garner, 1982). Thus, it is likely that self-discrepancies function as vulnerability factors in combination with other influences. For instance, research by Chaiken, Pliner, and their colleagues (Chaiken \& Pliner, 1987;
Mori et al., 1987; Pliner, Chaiken, \& Flett, 1990) has indicated that cultural influences as well as self-presentational concerns could give rise to a chronic pattern of restricted eating that, in turn, might increase one's risk for developing more pathological eating behavior patterns. Women wishing to enhance others' perceptions of their desirable feminine characteristics (or their self-perceptions of femininity) might attempt to attain a certain appearance by eating lightly. Thinness or attractiveness, as chronically accessible self-guides, will be activated by the social environment and will participate in determining perceptions of that environment. This mutual influence of selfevaluation and social and interpersonal factors would serve to increase the likelihood that the individual would encounter cues activating accessible self-standards for appearance, in turn increasing efforts at self-regulation. Over time, maladaptive eating behaviors could emerge from such a sequence of events. Likewise, to the extent that this process operated for men, they would also be expected to manifest body dissatisfaction and disordered eating behavior, but within the intrapsychic, interpersonal, and cultural contexts of their own lives. We suggest, then, as experimental studies of self-discrepancies in depression and anxiety have indicated (Strauman, 1989b), that selfguides may function as common pathways in which the motivational, cognitive, and social cultural antecedents of eating problems are combined.

It is important to acknowledge the limitations of the present research. First, the correlational nature of our studies permits only the inference that self-discrepancies are reliably associated with body dissatisfaction and disordered eating. Complementary investigations are needed to establish the validity of the developmental model on which these studies were based (and the contributory causal hypotheses implied in our model). Second, although we have no reason to doubt the generalizability of the findings we observed in our college-age samples, it is important for subsequent research to demonstrate that self-discrepancies also function as vulnerability factors within individuals characterized by more severe manifestations of maladaptive eating behaviors. In addition, studies of the relation between self-beliefs and other critical aspects of body image, such as visual and visceral perception, should be undertaken to learn more about the interactions among the range of psychological processes implicated in vulnerability to body dissatisfaction and maladaptive eating. Nonetheless, the present research is an initial step toward the development of more comprehensive psychological models for the etiology of body dissatisfaction and eating-related problems.

\section{References}

American Psychiatric Association. (1987). Diagnostic and statistical manual of mental disorders (3rd ed., rev). Washington, DC: Author. Andersen, A. E. (1986). Males with eating disorders. In F. E. Larocca (Ed.), Eating disorders. (New Directions for Mental Health Series No. 31, pp. 39-46). San Francisco: Jossey-Bass.

Bandura, A. (1982). The self and mechanisms of agency. In J. Suls (Ed), Psychological perspectives on the self (Vol. 1, pp. 3-39). Hillsdale, NJ: Erlbaum.

Bargh, J. A. (1984). Automatic and conscious processing of social in- 
formation. In R. S. Wyer, Jr., \& T. K. Srull (Eds.), Handbook of social cognition (Vol. 3, pp. 1-43). Hillsdale, NJ: Erlbaum.

Boskind-Lodahl, M. (1976). Cinderella's stepsisters: A feminist perspective on anorexia nervosa and bulimia. Signs: Journal of Women in Culture and Society, 2, 342-356.

Bray, G. (1986). Effects of obesity on health and happiness. In K. Brownell \& J. Foreyt (Eds.), Handbook of eating disorders: Physiology, psychology and treatment of obesity anorexia, and bulimia (pp. 3-44). New York: Basic Books.

Bruch, H. (1973). Eating disorders. New York: Basic Books.

Bruch, H. (1982). Anorexia nervosa: Theory and therapy. American Journal of Psychiatry, 139, 1531-1538.

Cash, T. F., \& Green, G. K. (1986). Body weight and body image among college women: Perception, cognition, and affect. Journal of Personality Assessment, 50, 290-301.

Chaiken, S., \& Pliner, P. (1987). Women, but not men, are what they eat: The effect of meal size and gender on perceived femininity and masculinity. Personality and Social Psychology Bulletin, 13, 166-176.

Cohen, J., \& Cohen, P. (1975). Applied multiple regression/correlation analysis for the behavioral sciences. Hillsdale, $\mathrm{NJ}$ : Erlbaum.

Cooper, P. J., Taylor, M. J., Cooper, Z., \& Fairburn, C. (1987). The development and validation of the Body Shape Questionnaire. International Journal of Eating Disorders, 6, 485-494.

Fransella, F., \& Button, E. (1983). The "construing" of self and body size in relation to maintenance of weight gain in anorexia nervosa. In P. Darby, P. Garfinkel, D. Garner, \& D. Coscina (Eds.), Anorexia nervosa: Recent developments (pp. 107-116). New York: Alan R. Liss.

Fransella, F., \& Crisp, A. H. (1979). Comparisons of weight concepts in groups of neurotic, normal and anorexic females. British Journal of Psychiatry, 134, 79-86.

Garfinkel, P. E., \& Garner, D. M. (1982). Anorexia nervosa: A multidimensional perspective. New York: Brunner/Mazel.

Garner, D. M., \& Garfinkel, P. (1979). The Eating Attitudes Test: An index of the symptoms of anorexia nervosa. Psychological Medicine, 9. 273-279.

Garner, D. M., Olmsted, M. P., Bohr, Y., \& Garfinkel, P. E. (1982). The Eating Attitudes Test: Psychometric features and clinical correlates. Psychological Medicine, 12, 871-878.

Garrow, J. S. (1986). Physiological aspects of obesity. In K. Brownell \& J. Foreyt (Eds.), Handbook of eating disorders: Physiology, psychology, and treatment of obesity, anorexia, and bulimia (pp. 45-62). New York: Basic Books.

Hawkins, R. C., \& Clement, P. F. (1980). Development and construct validation of a self-report measure of binge eating tendencies. $A d$ dictive Behaviors, 5, 219-226.

Herman, C. P., \& Polivy, J. (1980). Restrained and unrestrained eating. In A. J. Stunkard (Ed.), Obesity: Basic mechanisms and treatment (pp. 208-225). Philadelphia: W. B. Saunders.

Higgins, E. T. (1987). Self-discrepancy: A theory relating self and affect. Psychological Review, 94, 319-340.

Higgins, E. T. (1989a). Continuities and discontinuities in self-regulatory and self-evaluative processes: A developmental theory relating self and affect. Joturnal of Personality, 57, 407-444.

Higgins, E. T. (1989b). Risks and trade-offs in self-regulatory and selfevaluative processes: A developmental model. In M. R. Gunnar \& A. Sroufe (Eds.), Minnesota Symposium on Child Psychology (pp. 101-138). Hillsdale, NJ: Erlbaum.

Higgins, E. T. (1989c). Self-discrepancy theory: What patterns of selfbeliefs cause people to suffer? In L. Berkowitz (Ed), Advances in experimental social psychology (Vol. 22, pp. 93-136). San Diego, CA: Academic Press.

Higgins, E. T. (in press). Patterns of self-beliefs: The psychological significance of relations among the actual, ideal, ought, can, and future selves. In J. Olson \& M. Zanna (Eds.), Processes in self-perception: The Ontario Symposium. Hillsdale, NJ: Erlbaum.

Higgins, E. T., Bond, R., Klein, R., \& Strauman, T. (1986). Self-discrepancies and emotional vulnerability: How magnitude, accessibility and type of discrepancy influence affect. Journal of Personality and Social Psychology, 51, 5-15.

Higgins, E. T., \& Eccles-Parsons, J. (1983). Social cognition and the social life of the child: Stages as subcultures. In E. T. Higgins, D. N. Ruble, \& W. W. Hartup (Eds.), Social cognition and social development: A socio-cultural perspective (pp. 15-62). Cambridge, England: Cambridge University Press.

Higgins, E. T., King, G., \& Mavin, G. (1982). Individual construct accessibility and subjective impressions and recall. Journal of Personality and Social Psychology, 43, 35-47.

Higgins, E. T., Klein, R., \& Strauman, T. (1985). Self-concept discrepancy theory: A psychological model for distinguishing among different aspects of depression and anxiety. Social Cognition, 3, 51-76.

Hudson, J. I., Laffer, P. S., \& Pope, H. G. (1982). Bulimia related to affective disorder by family history and response to the dexamethasone suppression test. American Journal of Psychiatry, 139, 685-687.

Lee, N. F., Rush, A. J., \& Mitchell, J. E. (1985). Bulimia and depression. Journal of Affective Disorders, 9, 231-238.

Lerner, R. M., \& Karabenick, S. (1974). Physical attractiveness, body attitudes, and self-concept in late adolescents. Journal of Youth and Adolescence, 3, 307-316.

Lerner, R. M., Karabenick, S., \& Stuart, J. L. (1973). Relations among physical attractiveness, body attitudes, and self-concept in male and female college students. Journal of Psychology, 85, 119-129.

Markus, H., Hamill, R., \& Sentis, K. P. (1987). Thinking fat: Self-schemas for body weight and the processing of weight relevant information. Journal of Applied Social Psychology, 17, 50-71.

Metropolitan Life Insurance Company. (1983). Statistical bulletin. New York: Author.

Mori, D., Chaiken, S., \& Pliner, P. (1987). "Eating lightly" and the self-presentation of femininity. Journal of Personality and Social Psychology, 53, 693-702.

Parke, R. D., \& Slaby, R. G. (1983). The development of aggression. In P. H. Mussen (Ed), Handbook of child psychology, Volume IV: Socialization, personality, and social development (pp. 547-641). New York: Wiley.

Pliner, P., Chaiken, S., \& Flett, G. L. (1990). Gender differences in concern with body weight and physical appearance over the life span. Personality and Social Psychology Bulletin, 16, 263-273.

Polivy, J., Herman, C., Jazwinski, C., \& Olmsted, M. (1984). Restraint and binge-eating. In R. Hawkins, W. Fremouw, \& P. Clement (Eds.), Binge eating: Theory, research, and treatment (pp. 104-122). New York: Springer.

Powers, P. S., Schulman, R. G., Gleghorn, A. A., \& Prange, M. E. (1987). Perceptual and cognitive abnormalities in bulimia. American Journal of Psychiatry, 144, 1456-1460.

Rodin, J., Silberstein, L. R., \& Striegel-Moore, R. H. (1985). Women and weight: A normative discontent. In T. B. Sonderegger (Ed), Psychology and gender: Nebraska Symposium on Motivation (pp. 267307). Lincoln: University of Nebraska Press.

Rothbart, M. K., \& Rothbart, M. (1976). Birth order, sex of child, and maternal helpgiving. Sex Roles, 2, 39-46.

Ruble, D. N. (1983). The development of social comparison processes and their role in achievement-related self-socialization. In E. T. Higgins, D. N. Ruble, \& W. W. Hartup (Eds.), Social cognition and social development: A socio-cultural perspective (pp. 134-157). Cambridge, England: Cambridge University Press.

Rutter, M., \& Garmezy, N. (1983). Developmental psychopathology. In P. H. Mussen (Ed.), Handbook of child psychology, Volume IV. Socia- 
lization, personality, and social development (pp. 775-911). New York: Wiley.

Simmons, R. G., \& Blythe, D. A. (1987). Moving into adolescence: The impact of pubertal change and social context. New York: Aldine de Gruyter.

Strauman, T. J. (1989a). The paradox of the self: A psychodynamic/social-cognitive integration. In R. C. Curtis(Ed.), Self-defeating behavior: Experimental findings, clinical impressions, and practical implications (pp. 311-339). New York: Plenum Press.

Strauman, T. J. (1989b). Self-discrepancies in clinical depression and social phobia: Cognitive structures that underlie emotional disorders? Journal of Abnormal Psychology, 98, 14-22.

Strauman, T. J., \& Higgins, E. T. (1987). Automatic activation of selfdiscrepancies and emotional syndromes: When cognitive structures influence affect. Journal of Personality and Social Psychology, 53, 1004-1014.

Strauman, T. J., \& Higgins, E. T. (1988). Self-discrepancies as predictors of vulnerability to distinct syndromes of chronic emotional distress. Journal of Personality, 56, 685-707.

Strauss, J., \& Ryan, R. M. (1987). Autonomy disturbances in subtypes of anorexia nervosa. Journal of Abnormal Psychology, 96, 254-258.
Strober, M. (1982). Locus of control, psychopathology, and weight gain in juvenile anorexia nervosa. Journal of Abnormal Child Psychology, 10,97-106.

Strober, M. (1986). Anorexia nervosa: History and psychological concepts. In K. Brownell \& J. Foreyt (Eds.), Handbook of eating disorders: Physiology, psychology, and treatment of obesity, anorexia, and bulimia (pp. 231-246). New York: Basic Books.

Strober, M., \& Goldenberg, I. (1981). Ego boundary disturbance in juvenile anorexia nervosa. Journal of Clinical Psychology, 37, 433438.

Sugarman, A., Quinlan, D., \& Devenis, L. (1982). Ego boundary disturbance in anorexia nervosa: Preliminary findings. Journal of Personality Assessment, 46, 455-461.

Walsh, B. T., Stewart, J. W., Wright, L., Harrison, W., Roose, S. D., \& Glassman, A. H. (1982). Treatment of bulimia with monoamine oxidase inhibitors. American Journal of Psychiatry, 139, 1629-1630.

Received May 8, 1990

Revision received January 2,1991

Accepted February 14, 1991 .

\section{Low Publication Prices for APA Members and Affiliates}

Keeping You Up to Date: All APA members (Fellows, Members, and Associates, and Student Affiliates) receive--as part of their annual dues--subscriptions to the American Psychologist and the APA Monitor.

High School Teacher and Foreign Affiliates receive subscriptions to the APA Monitor and they can subscribe to the American Psychologist at a significantly reduced rate.

In addition, members and affiliates are eligible for savings of up to $60 \%$ on other APA journals, as well as significant discounts on subscriptions from cooperating societies and publishers (e.g., the British Psychological Society, the American Sociological Association, and Human Sciences Press).

Essential Resources: APA members and affiliates receive special rates for purchases of APA books, including Computer Use in Psychology: A Directory of Software, the Master Lectures, and Journals in Psychology: A Resource Listing for Authors.

Other Benefits of Membership: Membership in APA also provides eligibility for low-cost insurance plans covering life; medical and income protection; hospital indemnity; accident and travel; Keogh retirement; office overhead; and student/school, professional, and liability.

For more information, write to American Psychological Association, Membership Services, 1200 Seventeenth Street NW, Washington, DC 20036, USA or call (703) 247-7760 (collect calls cannot be accepted). 